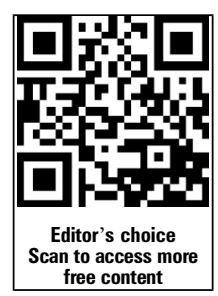
Scan to access m
free content
- Additional material is published online only. To view please visit the journal online (http://dx.doi.org/10.1136/ oemed-2014-102798).

\section{Occupational and}

Environmental Epidemiology Branch, Division of Cancer Epidemiology and Genetics, National Cancer Institute, Bethesda, Maryland, USA ${ }^{2}$ Yale University School of Public Health, New Haven, Connecticut, USA

${ }^{3}$ Department of Biological

Sciences, North Carolina State University, Raleigh, North

Carolina, USA

${ }^{4}$ Epidemiology Branch,

National Institute of

Environmental Health Sciences, Research Triangle Park, North Carolina, USA

${ }^{5}$ Biostatistics Branch, Division of Cancer Epidemiology and Genetics, National Cancer Institute, Bethesda, Maryland, USA

\section{Correspondence to}

Catherine C Lerro,

Occupational and

Environmental Epidemiology Branch, Division of Cancer Epidemiology and Genetics, National Cancer Institute, 9609 Medical Center Drive, 6E624,

MSC 7991, Bethesda, MD 20892-7991, USA; lerrocc@mail.nih.gov

Received 30 December 2014 Revised 5 May 2015 Accepted 22 June 2015 Published Online First 6 July 2015

\section{CrossMark}

\footnotetext{
To cite: Lerro CC, Koutros S, Andreotti G, et al. Occup Environ Med 2015;72:736-744.
}

\title{
Organophosphate insecticide use and cancer incidence among spouses of pesticide applicators in the Agricultural Health Study
}

\author{
Catherine C Lerro, ${ }^{1,2}$ Stella Koutros, ${ }_{1}^{1}$ Gabriella Andreotti, ${ }^{1}$ Melissa C Friesen, ${ }^{1}$ \\ Michael C Alavanja, ${ }^{1}$ Aaron Blair, ${ }^{1}$ Jane A Hoppin, ${ }^{3}$ Dale P Sandler, ${ }^{4}$ Jay H Lubin, ${ }^{5}$ \\ Xiaomei $\mathrm{Ma}^{2}$ Yawei Zhang, ${ }^{2}$ Laura E Beane Freeman ${ }^{1}$
}

\begin{abstract}
Objectives Organophosphates (OPs) are among the most commonly used insecticides. OPs have been linked to cancer risk in some epidemiological studies, which have been largely conducted in predominantly male populations. We evaluated personal use of specific OPs and cancer incidence among female spouses of pesticide applicators in the prospective Agricultural Health Study cohort.
\end{abstract}

Methods At enrolment (1993-1997), spouses provided information about ever use of specific pesticides, including $10 \mathrm{OPs}$, demographic information, reproductive health history and other potential confounders. We used Poisson regression to estimate relative risks (RRs) and $95 \% \mathrm{Cls}$ for all cancers diagnosed through 2010 for North Carolina and through 2011 for lowa.

Results Among 30003 women, 25.9\% reported OP use, and 718 OP-exposed women were diagnosed with cancer during the follow-up period. Any OP use was associated with an elevated risk of breast cancer ( $R R=1.20,95 \% \mathrm{Cl} 1.01$ to 1.43 ). Malathion, the most commonly reported $\mathrm{OP}$, was associated with increased risk of thyroid cancer ( $R R=2.04,95 \% \mathrm{Cl} 1.14$ to 3.63 ) and decreased risk of non-Hodgkin lymphoma ( $R R=0.64$, $95 \% \mathrm{Cl} 0.41$ to 0.99 ). Diazinon use was associated with ovarian cancer ( $R R=1.87,95 \% \mathrm{Cl} 1.02$ to 3.43 ).

Conclusions We observed increased risk with OP use for several hormonally-related cancers, including breast, thyroid and ovary, suggesting potential for hormonallymediated effects. This study represents the first comprehensive analysis of OP use and cancer risk among women, and thus demonstrates a need for further evaluation.

\section{BACKGROUND}

Organophosphates (OPs) are among the most commonly sold and used active insecticide ingredients in the USA in all market sectors (ie, agriculture, home and garden, industrial, commercial and government), and currently comprise approximately $35 \%$ of insecticides used. ${ }^{1}$ Some OPs, such as malathion, are registered for outdoor residential use in the USA, ${ }^{2}$ while others, such as diazinon and chlorpyrifos, were once registered for residential use, but now only agricultural use is allowed. ${ }^{3}{ }^{4}$ Selected OPs are used widely in the USA and abroad in public health programmes for mosquito control. ${ }^{5}$

\section{What this paper adds}

- Organophosphates are among the most commonly used insecticides.

- Though organophosphates have been associated with increased cancer risk, there have been no prospective studies examining use of individual organophosphate insecticides and risk of multiple cancer sites in women.

- We observed increased risk with organophosphate insecticide use for several hormonally-mediated cancers, including breast, thyroid and ovary.

- Our results suggest the potential for hormonally-mediated effects of organophosphate insecticides with respect to cancer risk among women.

The International Agency for Research on Cancer classifies malathion and diazinon as probably carcinogenic to humans (group 2A) and dichlorvos, parathion, and tetrachlorvinphos as possibly carcinogenic to humans (group 2B), ${ }^{6}$ with the US Environmental Protection Agency additionally classifying parathion as a possible human carcinogen. ${ }^{7}$

Increased cancer risk has been associated with several OP insecticides in epidemiological studies, including case-control studies in the USA, ${ }^{8}$ Canada ${ }^{9}$ and Italy, ${ }^{10}$ nested case-control studies of structural pest control workers in Florida ${ }^{11}$ and farm workers in California, ${ }^{12}$ and, more recently, among licensed pesticide applicators in the prospective Agricultural Health Study (AHS) cohort. AHS investigators have linked the use of diazinon, chlorpyrifos and terbufos to lung cancer, ${ }^{13-15}$ use of diazinon, terbufos, fonofos and malathion to leukaemia, ${ }^{14-17}$ and use of terbufos to non-Hodgkin lymphoma (NHL) overall, as well as to specific NHL subtypes. ${ }^{18}$ Additionally, increases in aggressive prostate cancer have been observed among male applicators who were using terbufos, fonofos and malathion. ${ }^{19}$ Many studies have focused on occupational exposure among farmers; however, OP insecticides are also widely used by others occupationally engaged in pest control, as well as residentially in the general population.

Studies of OP use and cancer outcomes have largely been conducted in predominantly male 
populations. Consequently, little is known about the potential impact of personal OP use among women, specifically on the development of female cancers, despite the fact that OPs as a class are thought to have endocrine disrupting properties. ${ }^{20-22}$ Moreover, many of the cancer sites to be examined, including breast, lung, ovary, uterus and thyroid, are of major public health importance in the USA, because they are commonly diagnosed and are important contributors to cancer deaths among women. ${ }^{23}$ In this analysis, we plan to evaluate the association between self-reported personal use of OP insecticides among spouses of pesticide applicators and subsequent cancer risk.

\section{METHODS}

\section{Study population}

The AHS cohort has been described elsewhere in detail. ${ }^{24}$ Briefly, 52394 private pesticide applicators (mainly farmers) and 4916 commercial pesticide applicators were recruited and enrolled during 1993-1997 in Iowa and North Carolina when they obtained or renewed their licenses to apply restricted use pesticides. Private applicators who indicated at enrolment that they were married were asked to have their spouse complete a take-home enrolment questionnaire focusing on farm exposures and general health, and a second questionnaire focusing on reproductive health history. The 32345 spouses of private applicators who responded to the enrolment questionnaire are the focus of this study.

\section{Exposure assessment}

Use of OP insecticides and other potential confounders were assessed at enrolment using the spouse questionnaire, available at http://aghealth.nih.gov/background/questionnaires.html. Questions about pesticide use for spouses of pesticide applicators were asked as follows: 'During your lifetime, have you ever personally mixed or applied [pesticide]? (Include pesticides used for farm use, commercial application and personal use in your home or garden.)'. They were prompted for specific pesticides using the active ingredient name and one or more trade names. Chemicals were grouped on the questionnaire according to functional class (insecticides, fungicides, herbicides, etc). Spouses self-reported lifetime ever use of 50 pesticides, including $10 \mathrm{OP}$ insecticides (chlorpyrifos, coumaphos, diazinon, dichlorvos, fonofos, malathion, parathion, phorate, terbufos, trichlorfon). If any of these OPs were reported, the spouse was considered exposed to OPs as a chemical class. If they reported no exposure to any OP they were considered unexposed. Otherwise, they were considered to be missing for exposure to the chemical class grouping.

\section{Cancer follow-up}

Incident cancer cases were ascertained via regular linkage with Iowa and North Carolina state cancer registries. Cancer site was classified according to the International Classification of Diseases for Oncology (third revision), and lymphoma subtypes were classified according to the original Surveillance, Epidemiology and End Results Lymphoma Subtype Recode. We analysed first primary cancers diagnosed from the date of enrolment interview through date of death, movement out of state, or last date of study follow-up (31 December 2011 for Iowa, 31 December 2010 for North Carolina, USA), whichever was earliest. Our analysis included cancers with malignant behaviour, as well as in situ bladder cancers, which were included in the analysis, as per the standard grouping for bladder cancer. The study protocol was approved by all relevant institutional review boards.

\section{Statistical analysis}

We excluded male spouses as they were few $(n=220)$, and women were the focus of our evaluation. We additionally excluded women with cancer diagnoses prior to enrolment $(n=907)$, those with missing or zero person-years of follow-up $(n=110)$ and women with missing information for all 10 OPs $(n=1105)$, leaving 30003 female spouses available for analysis. We excluded persons missing information for the OP of interest for specific analyses. For analyses of ovarian and uterine cancer, women were censored at date of oophorectomy or hysterectomy, or excluded if they had an oophorectomy $(n=3074)$ or hysterectomy $(\mathrm{n}=5208)$ prior to study enrolment.

Relative risks (RRs) and 95\% CIs were estimated using Poisson regression in SAS V.9.3 (SAS Institute, Inc, Cary, North Carolina, USA) for all cancer sites combined and specific sites where sample size allowed ( $\mathrm{n} \geq 10$ exposed cases). For the evaluation of use of any OPs as a class, no OP use was the referent category. For individual chemical analyses, persons reporting no use of the specific OP were included in the referent category. We conducted sensitivity analyses comparing those who applied an individual OP to those who never applied any OP (referent).

We adjusted all models for age (continuous), state of residence (Iowa or North Carolina), cigarette pack-years smoked as reported at enrolment (never smoker, pack-year quartiles: $\leq 1.5$, $1.51-6.625,6.626-18,>18$, missing), race (white, other, missing), alcohol use (never, less than once per month, one to three times per month, once per week or more, missing), educational attainment (high school degree or less, some college, college graduate, missing), body mass index (BMI) $(\leq 25,25.1-$ $30,>30$, missing) and family history of cancer (yes, no, missing; specific cancer site where available). We also controlled for being the person who usually treats the home or lawn for pests, for ever use of specific pesticides most highly correlated with OP use (Spearman $\rho>0.40$; online supplementary table S1) and pesticides previously found to be associated with specific cancer outcomes in the AHS. ${ }^{25}$ In analyses of cancers of the breast, ovary and uterus, as well as all sites combined, we additionally adjusted for menopausal status at enrolment (no, before age 50 years, after age 50 years, missing), number of live births $(0$, $1,2,3,4^{+}$, missing), and ever use of oral contraceptives at enrolment (yes, no, missing). We additionally explored inclusion of number of live births prior to the age of 30 years, and the use of hormone replacement therapy among postmenopausal women. These variables did not appreciably alter our results and thus were not included in the final models. We considered family history of cancer as a potential effect modifier, but interaction terms did not reach statistical significance in any model. We also considered adjusting for smoking using other metrics (eg, smoking duration in years, current/former/never use), but the results were similar to adjustment for pack-years smoked.

Breast cancers were examined by estrogen receptor (ER) and progesterone receptor (PR) status. For female cancer sites (breast, ovary, and uterus), we examined the statistical interaction between OP use and menopausal status at enrolment, and additionally performed stratified analyses by menopausal status at enrolment. We conducted sensitivity analyses restricting to cases diagnosed more than 5 years after enrolment, and also restricted to women who reported any pesticide application. We also performed analyses in which we did not control for home and lawn use, to ensure we were not over-adjusting for $\mathrm{OP}$ and correlated pesticide use. Finally, we stratified results by BMI $(\leq 25,>25)$ to examine whether BMI might modify associations. All tests were two sided with $\alpha=0.05$. 
Table 1 Selected characteristics of AHS spouses at enrolment with valid OP use information ( $\left.n=29325^{*}\right)$, stratified by ever use of OP insecticides

\begin{tabular}{|c|c|c|c|c|c|c|c|}
\hline & \multirow{3}{*}{\multicolumn{2}{|c|}{$\begin{array}{l}\text { Total } \\
\mathrm{N}=29325\end{array}$}} & \multicolumn{4}{|c|}{ Any OP use } & \multirow[b]{4}{*}{ p Value } \\
\hline & & & \multirow{2}{*}{\multicolumn{2}{|c|}{$\begin{array}{l}\text { No } \\
N=21736\end{array}$}} & \multirow{2}{*}{\multicolumn{2}{|c|}{$\begin{array}{l}\text { Yes } \\
\mathrm{N}=7589\end{array}$}} & \\
\hline & & & & & & & \\
\hline & $\mathrm{N}$ & Per cent & $\mathrm{N}$ & Per cent & $\mathrm{N}$ & Per cent & \\
\hline \multicolumn{8}{|l|}{ Age at enrolment } \\
\hline$\leq 35$ & 5740 & 19.6 & 4743 & 21.8 & 997 & 13.1 & \multirow[t]{4}{*}{$<0.01$} \\
\hline $36-45$ & 8829 & 30.1 & 6465 & 29.7 & 2364 & 31.2 & \\
\hline $46-55$ & 7493 & 25.6 & 5172 & 23.8 & 2321 & 30.6 & \\
\hline $56+$ & 7263 & 24.8 & 5356 & 24.6 & 1907 & 25.1 & \\
\hline \multicolumn{8}{|l|}{ State } \\
\hline lowa & 19880 & 67.8 & 14323 & 65.9 & 5557 & 73.2 & \multirow[t]{2}{*}{$<0.01$} \\
\hline North Carolina & 9445 & 32.2 & 7413 & 34.1 & 2032 & 26.8 & \\
\hline \multicolumn{8}{|l|}{ Race } \\
\hline White & 28757 & 98.1 & 21208 & 97.6 & 7549 & 99.5 & \multirow[t]{3}{*}{$<0.01$} \\
\hline Other & 520 & 1.8 & 489 & 2.3 & 31 & 0.4 & \\
\hline Missing & 48 & 0.2 & 39 & 0.2 & 9 & 0.1 & \\
\hline \multicolumn{8}{|c|}{ Cigarette smoking (pack-years) } \\
\hline Never smoker & 20607 & 70.3 & 15304 & 70.4 & 5303 & 69.9 & \multirow[t]{6}{*}{0.06} \\
\hline Q1: $\leq 1.5$ & 1894 & 6.5 & 1361 & 6.3 & 533 & 7.0 & \\
\hline Q2: 1.51-6.625 & 1973 & 6.7 & 1456 & 6.7 & 517 & 6.8 & \\
\hline Q3: 6.626-18 & 2049 & 7.0 & 1551 & 7.1 & 498 & 6.6 & \\
\hline Q4: >18 & 1802 & 6.1 & 1311 & 6.0 & 491 & 6.5 & \\
\hline Missing & 1000 & 3.4 & 753 & 3.5 & 247 & 3.3 & \\
\hline \multicolumn{8}{|l|}{ Educational attainment } \\
\hline High school or less & 11983 & 40.9 & 9117 & 41.9 & 2866 & 37.8 & \multirow[t]{4}{*}{$<0.01$} \\
\hline Some college & 8010 & 27.3 & 5914 & 27.2 & 2096 & 27.6 & \\
\hline College graduate & 6302 & 21.5 & 4623 & 21.3 & 1679 & 22.1 & \\
\hline Other/missing & 3030 & 10.3 & 2082 & 9.6 & 948 & 12.5 & \\
\hline \multicolumn{8}{|l|}{ Alcohol use } \\
\hline Never & 13135 & 44.8 & 10095 & 46.4 & 3040 & 40.0 & \multirow[t]{5}{*}{$<0.01$} \\
\hline Less than once/month & 7799 & 26.6 & 5667 & 26.0 & 2132 & 28.1 & \\
\hline $1-3$ times/month & 4579 & 15.6 & 3321 & 15.3 & 1258 & 16.6 & \\
\hline 1 time/week or more & 3480 & 11.9 & 2401 & 11.0 & 1079 & 14.2 & \\
\hline Missing & 332 & 1.1 & 252 & 1.2 & 80 & 1.1 & \\
\hline \multicolumn{8}{|l|}{ Body mass index } \\
\hline$\leq 25$ & 12853 & 43.8 & 9514 & 43.8 & 3339 & 44.0 & $<0.01$ \\
\hline $25.1-30$ & 8285 & 28.3 & 5936 & 27.3 & 2349 & 31.0 & \\
\hline$>30$ & 4795 & 16.4 & 3491 & 16.1 & 1304 & 17.2 & \\
\hline Missing & 3392 & 11.6 & 2795 & 12.9 & 597 & 7.9 & \\
\hline Family history of cancer & & & & & & & \\
\hline No & 14356 & 49.0 & 10943 & 50.4 & 3413 & 45.0 & $<0.01$ \\
\hline Yes & 14426 & 49.2 & 10343 & 47.6 & 4083 & 53.8 & \\
\hline Missing & 543 & 1.9 & 450 & 2.1 & 93 & 1.2 & \\
\hline Menopause at enrolment & & & & & & & \\
\hline No & 14841 & 50.6 & 11130 & 51.2 & 3711 & 48.9 & $<0.01$ \\
\hline Yes, before age 50 & 7086 & 24.2 & 5022 & 23.1 & 2064 & 27.2 & \\
\hline Yes, after age 50 & 4101 & 14.0 & 2870 & 13.2 & 1231 & 16.2 & \\
\hline Missing & 3297 & 11.2 & 2714 & 12.5 & 583 & 7.7 & \\
\hline Number of live births & & & & & & & \\
\hline 0 & 1554 & 5.3 & 1149 & 5.3 & 405 & 5.3 & $<0.01$ \\
\hline 1 & 2194 & 7.5 & 1711 & 7.9 & 483 & 6.4 & \\
\hline 2 & 8625 & 29.4 & 6347 & 29.2 & 2278 & 30.0 & \\
\hline 3 & 6961 & 23.7 & 4944 & 22.8 & 2017 & 26.6 & \\
\hline $4+$ & 5585 & 19.1 & 3949 & 18.2 & 1636 & 21.6 & \\
\hline Missing & 4406 & 15.0 & 3636 & 16.7 & 770 & 10.2 & \\
\hline
\end{tabular}


Table 1 Continued

\begin{tabular}{|c|c|c|c|c|c|c|c|}
\hline & \multirow{2}{*}{\multicolumn{2}{|c|}{$\begin{array}{l}\text { Total } \\
\mathrm{N}=29325\end{array}$}} & \multicolumn{4}{|c|}{ Any OP use } & \multirow[b]{3}{*}{ p Valuet } \\
\hline & & & \multicolumn{2}{|c|}{$\begin{array}{l}\text { No } \\
\mathrm{N}=21736\end{array}$} & \multicolumn{2}{|c|}{$\begin{array}{l}\text { Yes } \\
\mathrm{N}=7589\end{array}$} & \\
\hline & $\mathbf{N}$ & Per cent & $\mathbf{N}$ & Per cent & $\mathbf{N}$ & Per cent & \\
\hline \multicolumn{8}{|c|}{ Oral contraceptive use } \\
\hline Never & 6838 & 23.3 & 5049 & 23.2 & 1789 & 23.6 & \multirow[t]{3}{*}{$<0.01$} \\
\hline Ever & 19124 & 65.2 & 13938 & 64.1 & 5186 & 68.3 & \\
\hline Missing & 3363 & 11.5 & 2749 & 12.7 & 614 & 8.1 & \\
\hline \multicolumn{8}{|c|}{ Apply pesticides in home } \\
\hline No & 21164 & 72.2 & 16833 & 77.4 & 4331 & 57.1 & \multirow[t]{2}{*}{$<0.01$} \\
\hline Yes & 8161 & 27.8 & 4903 & 22.6 & 3258 & 42.9 & \\
\hline \multicolumn{8}{|c|}{ Apply pesticides on lawn/garden } \\
\hline No & 26158 & 89.2 & 20417 & 93.9 & 5741 & 75.7 & \multirow[t]{2}{*}{$<0.01$} \\
\hline Yes & 3167 & 10.8 & 1319 & 6.1 & 1848 & 24.4 & \\
\hline
\end{tabular}

\section{RESULTS}

Median follow-up time was 15.3 years. At enrolment, 25.9\% of female spouses with valid information on OP use reported ever using at least one OP insecticide (online supplementary table S1). The most commonly used OP insecticides were malathion (19.5\%) and diazinon (10.3\%). Table 1 describes selected demographic, health and behavioural characteristics of AHS spouses. Ever users of OPs were older, from Iowa, white, more highly educated, heavier users of alcohol and more overweight than non-users. They were also more likely to have had a family history of cancer, more live births and to have gone through menopause at enrolment. Ever users of OPs were also more likely to report being the one who usually treats the home and/ or lawn for pests. Lawn and home pesticide users were more likely to report herbicide use (data not shown).

Table 2 summarises the results for ever use of OPs and risk of cancers with $\mathrm{n} \geq 10$ exposed cases. Use of any $\mathrm{OP}(\mathrm{RR}=1.20$, $95 \%$ CI 1.01 to 1.43 ) was significantly associated with breast cancer. Chlorpyrifos use ( $R R=1.41,95 \%$ CI 1.00 to 1.99$)$ and terbufos use ( $\mathrm{RR}=1.52,95 \% \mathrm{CI} 0.97$ to 2.36$)$ were associated with non-significantly elevated risk of breast cancer. Chlorpyrifos was associated with a significantly increased risk of $\mathrm{ER}^{-} \mathrm{PR}^{-}$breast cancer $(\mathrm{RR}=2.26,95 \% \mathrm{CI} 1.07$ to 4.75$)$. Malathion use was associated with a significantly increased risk of thyroid cancer $(\mathrm{RR}=2.04,95 \% \mathrm{CI} 1.14$ to 3.63$)$ and decreased risk of NHL $(\mathrm{RR}=0.64,95 \%$ CI 0.41 to 0.99$)$. Diazinon use was associated with a significantly increased risk of ovarian cancer $(\mathrm{RR}=1.87,95 \% \mathrm{CI} 1.02$ to 3.43$)$. We observed no other associations between overall or specific OP use and cancer risk for any other site.

We stratified analyses for cancers of the breast, ovary and uterus based on self-reported menopausal status at enrolment (table 3), with 15144 women classified as premenopausal and 12216 as postmenopausal. Among postmenopausal women, we observed significantly elevated risk of breast cancer associated with use of any OP $(\mathrm{RR}=1.27,95 \% \mathrm{CI} 1.00$ to 1.62$)$, and nonsignificantly elevated breast cancer risk associated with chlorpyrifos $(\mathrm{RR}=1.53,95 \% \mathrm{CI} 0.96$ to 2.44$)$ and terbufos $(\mathrm{RR}=1.73$, $95 \%$ CI 0.93 to 3.21 ). Among women who used diazinon, we observed significantly elevated risk of ovarian cancer among premenopausal women $(\mathrm{RR}=3.26,95 \% \mathrm{CI} 1.31$ to 8.13$)$, but not postmenopausal women $(\mathrm{RR}=1.18,95 \% \mathrm{CI} 0.46$ to 3.03 , $P_{\text {interaction }}=0.06$ ). We observed significant interactions with menopausal status and malathion for ovarian cancer risk $\left(\mathrm{P}_{\text {interaction }}=0.04\right)$, and with menopausal status and diazinon for uterine cancer risk $\left(\mathrm{P}_{\text {interaction }}=0.03\right)$. The stratum-specific risk estimates were not statistically significant, but the RRs were elevated among premenopausal women.

When analyses were restricted to cancer cases $(n \geq 10)$ diagnosed at least 5 years after study enrolment $(n=29244)$, the results were mostly unchanged, with a few exceptions (table 4). The association between diazinon and ovarian cancer was no longer significant $(\mathrm{RR}=1.88$, 95\% CI 0.93 to 3.78$)$ but remained elevated ( $n=10$ exposed cases). We noted a statistically significant association between any OP use and multiple myeloma ( $\mathrm{RR}=3.00,95 \% \mathrm{CI} 1.08$ to 8.34$)$. Additionally, diazinon $(R R=1.24,95 \%$ CI 0.99 to 1.56$)$, coumaphos $(R R=1.64$, $95 \%$ CI 0.98 to 2.74$)$ and parathion $(\mathrm{RR}=1.72$, 95\% CI 0.99 to 2.99 ) were all associated with non-significantly elevated risk of breast cancer.

When we restricted our study population to spouses who reported any pesticide application $(n=16685)$, the results remained unchanged. Results were similar in sensitivity analyses in evaluation of individual OPs and using those who had never used any OP as the referent group. We also evaluated the impact of controlling for home and lawn pesticide use; the results were similar with and without control. Stratification by BMI revealed that the significant results in the models were more pronounced overall among normal weight women $(\mathrm{BMI} \leq 25)$, with the exception of the association with malathion use and NHL, which was stronger among women with BMI $>25$ (results not shown).

\section{DISCUSSION}

This is the first study, to our knowledge, to prospectively evaluate use of OPs and cancer at multiple sites among women. It also provides the first epidemiological evaluation of many female cancers, such as of the ovary and uterus, with this important chemical pesticide class. We observed increased risk of several hormonally-related cancers, including thyroid, ovary and breast.

We observed a strong association between malathion use and thyroid cancer. A previous study of male AHS private 
Table 2 RRs and $95 \% \mathrm{Cls}^{*}$ for ever use of OP insecticides, compared to never use, for various cancers among AHS spouses

\begin{tabular}{|c|c|c|c|c|c|c|c|c|c|c|c|c|c|c|c|c|}
\hline & \multirow[b]{2}{*}{$\mathrm{N}_{\text {total }}{ }^{\dagger}$} & \multicolumn{3}{|c|}{ Any OP } & \multicolumn{3}{|c|}{ Malathion } & \multicolumn{3}{|c|}{ Diazinon } & \multicolumn{3}{|c|}{ Chlorpyrifos } & \multicolumn{3}{|c|}{ Terbufos } \\
\hline & & $\mathrm{N} \ddagger$ & $\mathrm{RR}$ & $95 \% \mathrm{Cl}$ & $\mathrm{N}$ & RR & $95 \% \mathrm{Cl}$ & $\mathrm{N}$ & $\mathrm{RR}$ & $95 \% \mathrm{Cl}$ & N & $\mathrm{RR}$ & $95 \% \mathrm{Cl}$ & $N$ & RR & $95 \% \mathrm{Cl}$ \\
\hline All sites§ & 2712 & 718 & 1.08 & 0.97 to 1.21 & 558 & 1.03 & 0.92 to 1.15 & 277 & 1.04 & 0.91 to 1.18 & 108 & 1.03 & 0.81 to 1.3 & 88 & 1.26 & 0.94 to 1.69 \\
\hline Brain & 38 & 14 & 1.29 & 0.53 to 3.12 & 11 & 1.57 & 0.65 to 3.78 & & & & & & & & & \\
\hline Breast§ & 1059 & 296 & 1.20 & 1.01 to 1.43 & 223 & 1.05 & 0.88 to 1.26 & 118 & 1.14 & 0.93 to 1.38 & 50 & 1.41 & 1.00 to 1.99 & 37 & 1.52 & 0.97 to 2.36 \\
\hline$E R+P R+$ & 595 & 165 & 1.14 & 0.90 to 1.44 & 124 & 1.00 & 0.79 to 1.26 & 62 & 1.07 & 0.82 to 1.40 & 28 & 1.37 & 0.86 to 2.19 & 21 & 1.41 & 0.78 to 2.55 \\
\hline ER-PR- & 171 & 52 & 1.26 & 0.83 to 1.92 & 40 & 1.17 & 0.77 to 1.78 & 20 & 1.21 & 0.75 to 1.96 & 11 & 2.26 & 1.07 to 4.75 & & & \\
\hline Colon & 204 & 47 & 0.87 & 0.56 to 1.33 & 38 & 0.89 & 0.58 to 1.37 & 19 & 0.98 & 0.59 to 1.61 & & & & & & \\
\hline Leukaemia & 63 & 19 & 0.83 & 0.40 to 1.71 & 14 & 0.73 & 0.34 to 1.54 & & & & & & & & & \\
\hline Lung & 165 & 35 & 0.77 & 0.46 to 1.28 & 30 & 1.00 & 0.60 to 1.65 & 15 & 0.92 & 0.52 to 1.64 & & & & & & \\
\hline Melanoma & 117 & 30 & 0.98 & 0.57 to 1.67 & 23 & 0.90 & 0.52 to 1.53 & & & & & & & & & \\
\hline NHL & 194 & 53 & 1.01 & 0.66 to 1.53 & 34 & 0.64 & 0.41 to 0.99 & 18 & 0.93 & 0.56 to 1.56 & & & & 10 & 1.54 & 0.59 to 4.03 \\
\hline $\mathrm{FL}$ & 38 & 13 & 1.24 & 0.51 to 3.01 & & & & & & & & & & & & \\
\hline MM & 37 & 12 & 1.78 & 0.70 to 4.52 & & & & & & & & & & & & \\
\hline CLL/SLL/PLL/MCL & 35 & 10 & 1.15 & 0.43 to 3.09 & & & & & & & & & & & & \\
\hline Ovary§ & 85 & 23 & 1.46 & 0.78 to 2.71 & 16 & 0.89 & 0.48 to 1.67 & 13 & 1.87 & 1.02 to 3.43 & & & & & & \\
\hline Pancreas & 47 & 16 & 1.46 & 0.64 to 3.32 & 14 & 1.50 & 0.69 to 3.26 & & & & & & & & & \\
\hline Rectum & 61 & 15 & 1.23 & 0.56 to 2.68 & 12 & 0.92 & 0.43 to 1.97 & & & & & & & & & \\
\hline Thyroid & 91 & 24 & 1.27 & 0.70 to 2.30 & 22 & 2.04 & 1.14 to 3.63 & & & & & & & & & \\
\hline \multirow[t]{3}{*}{ Uterus§ } & 231 & 72 & 1.19 & 0.83 to 1.72 & 58 & 1.28 & 0.90 to 1.83 & 25 & 1.06 & 0.69 to 1.64 & 10 & 0.85 & 0.38 to 1.89 & & & \\
\hline & & \multicolumn{3}{|c|}{ Dichlorvos } & \multicolumn{3}{|c|}{ Phorate } & \multicolumn{3}{|c|}{ Fonofos } & \multicolumn{3}{|c|}{ Coumaphos } & \multicolumn{3}{|c|}{ Parathion } \\
\hline & $\mathrm{N}_{\text {total }}$ & N & RR & $95 \% \mathrm{Cl}$ & $\mathrm{N}$ & RR & $95 \% \mathrm{Cl}$ & $\mathrm{N}$ & RR & $95 \% \mathrm{Cl}$ & N & RR & $95 \% \mathrm{Cl}$ & $\mathrm{N}$ & RR & $95 \% \mathrm{Cl}$ \\
\hline All sites§ & 2712 & 81 & 1.08 & 0.86 to 1.35 & 55 & 0.81 & 0.59 to 1.10 & 54 & 0.86 & 0.61 to 1.20 & 39 & 1.08 & 0.78 to 1.49 & 34 & 1.18 & 0.83 to 1.66 \\
\hline Breast§ & 1059 & 33 & 1.19 & 0.84 to 1.70 & 22 & 0.88 & 0.54 to 1.42 & 17 & 0.65 & 0.36 to 1.15 & 18 & 1.30 & 0.81 to 2.08 & 14 & 1.26 & 0.74 to 2.15 \\
\hline$E R+P R+$ & 595 & 23 & 1.34 & 0.88 to 2.05 & 15 & 0.96 & 0.52 to 1.77 & 10 & 0.59 & 0.28 to 1.26 & 10 & 1.23 & 0.65 to 2.30 & & & \\
\hline
\end{tabular}

*Adjusted for age, race, state, pack-years smoked, family history of cancer, alcohol consumption, BMI, education, lawn/garden pesticide application and correlated/associated pesticide use.

tTotal cases.

§Additionally adjusted for menopause status at enrolment, number of live births and oral contraceptive use.

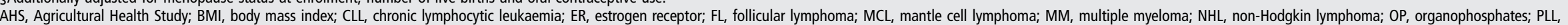
prolymphocytic leukaemia; PR, progesterone receptor; SLL, small lymphocytic lymphoma RR, relative risks. 


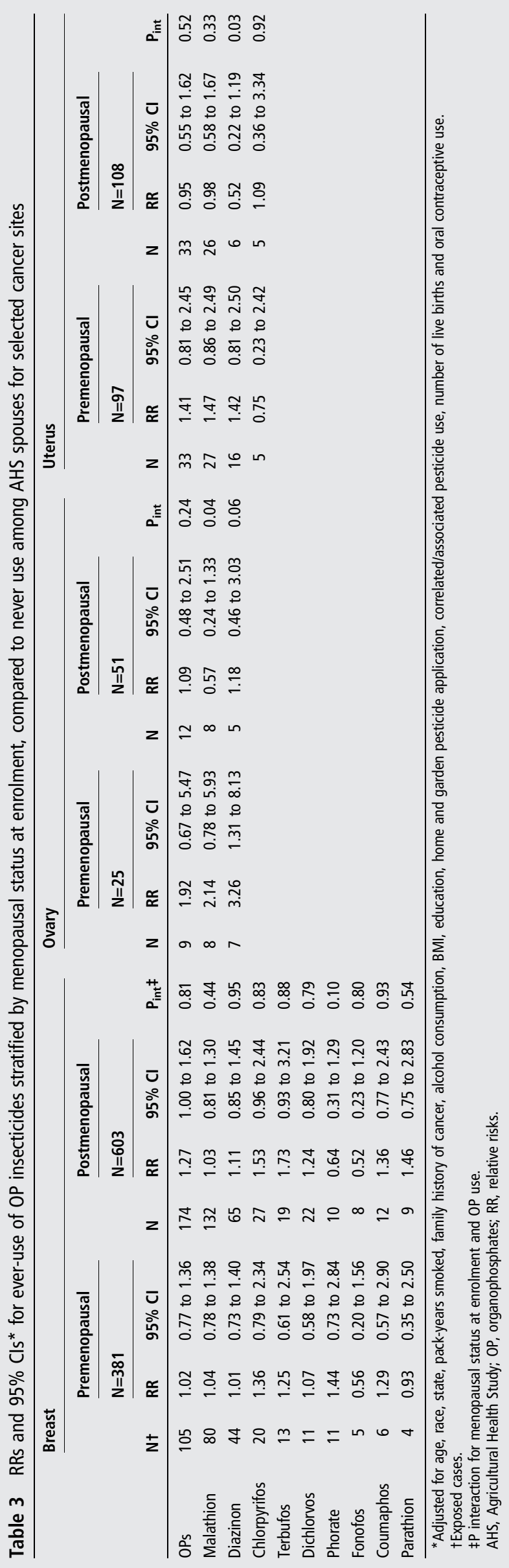

applicators found that malathion was associated with an increased prevalence of hypothyroidism $;{ }^{26}$ however, a similar study among female AHS spouses found no association with malathion and hypothyroidism, hyperthyroidism or other thyroid disease. ${ }^{27}$ Although hypothyroidism and hyperthyroidism have been hypothesised to be associated with thyroid cancer risk, the evidence has been somewhat inconsistent. ${ }^{28}{ }^{29}$ Low thyroid stimulating hormone levels are thought to be associated with future thyroid cancer risk; ${ }^{30}$ however, laboratory studies in rats found that malathion was associated with increased thyroid stimulating hormone secretion. ${ }^{31}$ In agricultural areas, nitrate exposure via diet and drinking water has been associated with thyroid cancer and hypothyroidism; ${ }^{32}$ we were not able to control for nitrate intake in our analyses.

Increased risk of ovarian cancer was associated with diazinon use, with a significantly increased risk among women who were premenopausal, but not postmenopausal, at enrolment. We also noted a significant interaction between menopausal status and malathion use for risk of ovarian cancer, with elevated risk among premenopausal women. However, this may be a chance finding, as there was no overall association between malathion and ovarian cancer. An excess of ovarian cancer has been reported among female pesticide applicators in the AHS, ${ }^{33}$ but the small number of female applicators precluded evaluation by specific pesticides. Diazinon has been shown to alter DNA methylation patterns in the promoter regions of several genes associated with cancer, and has been correlated with decreased DNA excision repair in vitro. ${ }^{34} 35$ Diazinon use has been associated with shortened relative telomere length in male AHS pesticide applicators. ${ }^{36}$ Diazinon has also been shown to exhibit estrogenic properties, and to have a genotoxic effect on human mucosal cells. ${ }^{37} 38$

Use of any OP, terbufos and chlorpyrifos was associated with non-significantly increased breast cancer risk for each, in our analyses. We also noted significantly increased risk associated with chlorpyrifos use and $\mathrm{ER}^{-} \mathrm{PR}^{-}$breast cancer. An AHS study with follow-up for breast cancers through 2000, with 309 cases, saw no significantly increased risk for personal use of any $\mathrm{OP}^{39}$ Our analysis of the updated cohort included 1059 accrued female breast cancer cases. A small registry-based case-control study of Hispanic farm workers in California examined use of pesticides and risk of breast cancer $(n=128$ cases), finding no association with diazinon and a suggestion of an association with malathion but no exposure-response. ${ }^{40}$ Many laboratory studies have noted associations between OPs and breast cancer in vitro and in vivo. OPs, particularly malathion and parathion, have been shown to induce malignant transformation of breast cells, ${ }^{41}{ }^{42}$ alter estrogen activity and ER transactivity, ${ }^{43}{ }^{44}$ and upregulate genes associated with carcinogenesis, sometimes in combination with estrogen. ${ }^{45}$

We observed a statistically significant inverse association with NHL and malathion use. A recent AHS analysis of male applicators found null associations with malathion use and NHL risk overall. ${ }^{18}$ Additionally, some case-control studies have shown a positive association for malathion use and NHL. ${ }^{9} 46 \quad 47$ Adjustment for other variables shown to be associated with NHL risk in farming populations, including whether or not our study participants grew up on a farm, their self-reported history of physician diagnosed allergies and contact with farm animals, did not alter the relationships in our study. Given these conflicting results and a lack of a plausible biological mechanism, it is unclear whether our observed inverse association between malathion and NHL is real or a chance finding. In sensitivity analyses restricting our population to those diagnosed more than 5 years 
Table 4 RRs and 95\% Cls* for ever use of OP insecticides, compared to never use, for various cancers diagnosed five or more years after study enrolment among AHS spouses

\begin{tabular}{|c|c|c|c|c|c|c|c|c|c|c|c|c|c|c|c|c|}
\hline & \multirow[b]{2}{*}{$\mathrm{N}_{\text {total }} \dagger^{\dagger}$} & \multicolumn{3}{|l|}{ OPs } & \multicolumn{3}{|c|}{ Malathion } & \multicolumn{3}{|c|}{ Diazinon } & \multicolumn{3}{|c|}{ Chlorpyrifos } & \multicolumn{3}{|c|}{ Terbufos } \\
\hline & & $\mathrm{N} \neq$ & RR & $95 \% \mathrm{Cl}$ & $\mathrm{N}$ & RR & $95 \% \mathrm{Cl}$ & $\mathrm{N}$ & RR & $95 \% \mathrm{Cl}$ & $\mathrm{N}$ & RR & $95 \% \mathrm{Cl}$ & $\mathrm{N}$ & RR & $95 \% \mathrm{Cl}$ \\
\hline All sites§ & 1953 & 528 & 1.08 & 0.94 to 1.23 & 411 & 1.04 & 0.91 to 1.18 & 209 & 1.08 & 0.93 to 1.25 & 82 & 1.05 & 0.79 to 1.38 & 64 & 1.17 & 0.83 to 1.66 \\
\hline Breast§ & 740 & 206 & 1.21 & 0.98 to 1.49 & 156 & 1.10 & 0.89 to 1.35 & 88 & 1.24 & 0.99 to 1.56 & 36 & 1.45 & 0.97 to 2.18 & 27 & 1.61 & 0.96 to 2.72 \\
\hline $\mathrm{ER}+\mathrm{PR}+$ & 431 & 122 & 1.22 & 0.93 to 1.61 & 95 & 1.11 & 0.85 to 1.45 & 46 & 1.10 & 0.81 to 1.51 & 19 & 1.20 & 0.68 to 2.11 & 15 & 1.39 & 0.68 to 2.81 \\
\hline ER-PR- & 115 & 35 & 1.19 & 0.71 to 1.99 & 25 & 1.04 & 0.62 to 1.74 & 16 & 1.48 & 0.86 to 2.55 & & & & & & \\
\hline Colon & 143 & 35 & 0.87 & 0.52 to 1.44 & 29 & 0.95 & 0.58 to 1.57 & 15 & 1.06 & 0.60 to 1.87 & & & & & & \\
\hline Leukaemia & 48 & 15 & 0.92 & 0.41 to 2.11 & 11 & 0.79 & 0.34 to 1.85 & & & & & & & & & \\
\hline Lung & 124 & 29 & 0.81 & 0.46 to 1.42 & 26 & 1.11 & 0.63 to 1.93 & 13 & 1.06 & 0.56 to 2.00 & & & & & & \\
\hline Melanoma & 72 & 21 & 1.02 & 0.53 to 1.97 & 15 & 0.82 & 0.42 to 1.59 & & & & & & & & & \\
\hline NHL & 152 & 46 & 1.10 & 0.69 to 1.74 & 27 & 0.60 & 0.37 to 0.98 & 17 & 1.14 & 0.66 to 1.96 & & & & & & \\
\hline $\mathrm{FL}$ & 30 & 11 & 1.02 & 0.38 to 2.76 & & & & & & & & & & & & \\
\hline MM & 27 & 11 & 3.00 & 1.08 to 8.34 & & & & & & & & & & & & \\
\hline Ovary§ & 61 & 18 & 1.55 & 0.75 to 3.18 & 15 & 1.28 & 0.64 to 2.56 & 10 & 1.88 & 0.93 to 3.78 & & & & & & \\
\hline Pancreas & 35 & 14 & 1.62 & 0.65 to 4.08 & 12 & 1.46 & 0.62 to 3.44 & & & & & & & & & \\
\hline Rectum & 44 & 11 & 0.96 & 0.39 to 2.41 & & & & & & & & & & & & \\
\hline Thyroid & 73 & 21 & 1.41 & 0.74 to 2.69 & 19 & 2.22 & 1.18 to 4.17 & & & & & & & & & \\
\hline Uterus§ & 170 & 47 & 1.03 & 0.66 to 1.59 & 37 & 1.09 & 0.71 to 1.67 & 15 & 0.81 & 0.47 to 1.41 & & & & & & \\
\hline
\end{tabular}

\begin{tabular}{|c|c|c|c|c|c|c|c|c|c|c|c|c|c|c|c|c|}
\hline & \multirow[b]{2}{*}{$\mathrm{N}_{\text {total }}$} & \multicolumn{3}{|c|}{ Dichlorvos } & \multicolumn{3}{|c|}{ Phorate } & \multicolumn{3}{|c|}{ Fonofos } & \multicolumn{3}{|c|}{ Coumaphos } & \multicolumn{3}{|c|}{ Parathion } \\
\hline & & $\mathrm{N}$ & RR & $95 \% \mathrm{Cl}$ & $\mathrm{N}$ & RR & $95 \% \mathrm{Cl}$ & $\mathrm{N}$ & RR & $95 \% \mathrm{Cl}$ & $N$ & RR & $95 \% \mathrm{Cl}$ & $\mathrm{N}$ & RR & $95 \% \mathrm{Cl}$ \\
\hline All sites§ & 1953 & 53 & 0.95 & 0.72 to 1.26 & 42 & 0.86 & 0.60 to 1.22 & 42 & 0.90 & 0.61 to 1.33 & 27 & 1.00 & 0.68 to 1.47 & 26 & 1.20 & 0.81 to 1.79 \\
\hline Breast§ & 740 & 19 & 1.05 & 0.66 to 1.67 & 16 & 0.94 & 0.53 to 1.65 & 12 & 0.66 & 0.33 to 1.31 & 15 & 1.64 & 0.98 to 2.74 & 13 & 1.72 & 0.99 to 2.99 \\
\hline $\mathrm{ER}+\mathrm{PR}+$ & 431 & 14 & 1.21 & 0.70 to 2.08 & 10 & 0.99 & 0.48 to 2.03 & & & & & & & & & \\
\hline
\end{tabular}

${ }^{*}$ Adjusted for age, race, state, pack-years smoked, family history of cancer, alcohol consumption, BMl, education, home and garden pesticide application and correlated/associated pesticide use.

tTotal cases.

${ }^{\ddagger}$ Exposed cases.

${ }^{\S}$ Additionally adjusted for menopause status at enrolment, number of live births, and oral contraceptive use.

AHS, Agricultural Health Study; BMI, body mass index; ER, estrogen receptor; FL, follicular Lymphoma; MM, multiple Myeloma; NHL, non-Hodgkin Lymphoma; OP, organophosphates;

$\mathrm{PR}$, progesterone receptor; RR, relative risks.

after study enrolment, we noted a positive association with use of any OP and multiple myeloma. No association was observed with any individual OP and multiple myeloma in a recent study of AHS applicators, ${ }^{18}$ though excesses of multiple myeloma have been noted among pesticide applicators and in farming populations. $^{33} 48$ The findings in our study were based on only a few exposed cases; therefore, further evaluations are needed to confirm these results.

The mechanism of pesticidal action of OPs involves inhibition of acetylcholinesterase activity. ${ }^{49}$ Excess acetylcholine as a result of OP exposure may act on cervical sympathetic neuronal nicotinic receptors, and activation of these neurones can promote thyroid hormone secretion via release of norepinephrine from the interfollicular adrenergic nerve endings. ${ }^{50-53}$ However, the potential mechanism of carcinogenesis may be unrelated to the mechanism of pesticidal action. Hypothesised carcinogenic mechanisms of OPs include increased cellular proliferation, ${ }^{42}$ oxidative stress ${ }^{54-56}$ and immunotoxicity. ${ }^{57}$ Given our findings with several hormonally-related cancers, it is also of note that OPs are thought to have endocrine disrupting properties. OPs may influence sex steroid hormone homeostasis, causing alterations in the levels of circulating and bioavailable sex hormones, ${ }^{58-61}$ and potentially impacting cellular proliferation and risk for hormone-related cancers. ${ }^{62}$ We noted that the associations for hormonally-related cancers were strongest among women with $\mathrm{BMI} \leq 25$. While there is some evidence that exposure to endocrine disrupting chemicals may impact body size, the relationship is not clear, and there are issues surrounding timing of exposure and reverse causation that make interpretation of these studies difficult. ${ }^{63}$ There is little information about a relationship between OP insecticide use and body size. A previous analysis in AHS examined the potential modifying effect of pesticides on the BMI-cancer association. There was a significant positive association between BMI and breast cancer in postmenopausal women who did not use OPs, but no association with BMI among those who did; however, the test for interaction was not significant. ${ }^{64}$

Strengths of our study include the longitudinal design with regular linkage to population registries for cancer and mortality outcomes, and little or no loss-to-follow-up, as well as information about the use of specific pesticides. Many epidemiological studies examine OPs as a class because of a small number of exposed cases, or because exposure to individual active ingredients is not evaluated. Owing to the prospective design of the AHS, there is no risk of differential reporting of pesticide use based on cancer outcome; any non-differential recall bias would bias the results toward the null. Blair et $a l^{65}$ assessed reliability of the AHS questionnaire among pesticide applicators; the level of agreement for ever pesticide use is quite high, ranging from $70 \%$ to greater than $90 \%$. Though this work was carried out among applicators, we believe the spouses' responses are similarly reliable. Spouses were prompted in the survey to mark all pesticides ever applied in their lifetime. Pesticide active ingredient and common trade names were listed in the survey. Because many of these women grew up on 
farms $(60 \%)$, it is likely they are familiar with regularly used pesticides. In focusing on spouses, we were able to examine cancer outcomes that are unique to (eg, ovary, uterus) or most common among women (eg, breast, thyroid).

A limitation of our analysis was sample size; only about one quarter of our sample reported OP use at enrolment. Owing to a small number of cases, we were unable to evaluate very rare cancer sites and may have limited power to evaluate cancer sites with low incidence in AHS. Although information was collected on known risk factors for female cancers (eg, menopausal status at enrolment, oral contraceptive use, parity), certain important details were either not provided (type of oral contraceptive or hormone replacement therapy), or available for only a portion of the cohort (time-varying menopausal status), and thus could not be assessed as potential confounders. Many spouses in our cohort applied more than one pesticide in their lifetime. We controlled for use of pesticides that were highly correlated with the OP of interest, as well as pesticides that had been associated with specific cancer sites in previous analyses, to minimise these possible sources of confounding by use of multiple pesticides. Because we examined the use of several OP insecticides and cancer outcomes, it is possible that the findings could be due to chance. We were only able to examine self-reported lifetime personal ever use, and had no information about duration or time period of use. The assumption that all exposures are equivalent may be incorrect, as patterns of OP use and chemical formulation may have changed over time. The inability to differentiate between high and low use may mask potential associations. We also only evaluated personal use of pesticides in this analysis and not to exposure from other sources. Based on how pesticide information was ascertained, we were not able to distinguish between occupational OP use on the farm versus residential indoor and outdoor uses. Many women reported being the person who applies pesticides to the home and lawn, but did not report personal use of specific pesticides or pesticides overall. We controlled for being the person applying home and lawn pesticides in order to capture this use. We were concerned about potential for over-adjustment for OP use, however, insecticides applied in the home at this time were primarily pyrethroids, and insecticides used on the lawn were primarily OPs. ${ }^{66}$ However, lawn use in our study reflected primarily herbicide and not insecticide use. Thus we feel confident we were not over-adjusting for OP use.

In the first study to prospectively examine use of OP insecticides and risk of multiple cancer sites among women, we observed associations with several cancer sites including thyroid, ovary and breast. Previous studies examining OP insecticide use and cancer have focused primarily on men, making ours a unique evaluation. The increased risks that we observed for hormonally-related cancers are consistent with the hypothesis that OPs might act as endocrine disruptors, although additional studies exploring this and other possible mechanisms are needed. Future studies should continue to consider use of individual OPs to fully understand their impact on cancer risk. Because of the ubiquitous use of OP insecticides in agricultural and in residential settings, future research should attempt to confirm these findings by assessing exposure-response trends, non-occupational environmental sources of OP exposure and hormonal changes in women exposed to OPs.

Acknowledgements Data in this analysis are based on the AHS data releases P1REL201209.00, P2REL201209 and P3REL201209.

Funding This work was supported by the Intramural Research Program of the National Institutes of Health, the National Cancer Institute (Z01-CP010119) and the National Institute of Environmental Health Sciences (Z01-ES049030).
Competing interests None declared.

Ethics approval National Cancer Institute Special Studies Institutional Review Board, Westat Institutional Review Board and the University of lowa Institutional Review Board-01.

Provenance and peer review Not commissioned; externally peer reviewed.

\section{REFERENCES}

1 Grube A, Donaldson D, Kiely T, et al. Pesticide industry sales and usage: 2006 and 2007 market estimates. Washington DC: Office of Pesticide Programs, US Environmental Protection Agency, 2011.

2 Reregistration Eligibility Decision (RED) for Malathion Case No. 0248. EPA 738-R-06-030. Washington DC: Prevention, Pesticides, and Toxic Substances (7508P), US Environmental Protection Agency, 2006.

3 Diazinon Summary Document Registration Review: Initial Docket Case Number 0238. EPA-HQ-OPP-2008-0351. Washington DC: Office of Pesticide Programs, US Environmental Protection Agency, 2008.

4 Chlorpyrifos Summary Document Registration Review: Initial Docket Case \#0100. EPA-HQ-OPP-2008-0850. Washington DC: Office of Pesticide Programs, US Environmental Protection Agency, 2009.

5 Mosquito Control: Malathion. US Enviromental Protection Agency, 2014. http:// www2.epa.gov/mosquitocontrol/malathion (accessed Sep 2014).

6 Agents classified by the IARC monographs. Vols 1-113. Lyon, France: International Agency for Research on Cancer, World Health Organization, 2015.

7 Integrated Risk Information System (IRIS) on parathion. Washington DC: Office of Research and Development, National Center for Environmental Assessment, US Environmental Protection Agency, 1999.

8 De Roos AJ, Zahm SH, Cantor KP, et al. Integrative assessment of multiple pesticides as risk factors for non-Hodgkin's lymphoma among men. Occup Environ Med 2003;60:E11.

9 McDuffie HH, Pahwa P, McLaughlin JR, et al. Non-Hodgkin's lymphoma and specific pesticide exposures in men: cross-Canada study of pesticides and health. Cancer Epidemiol Biomarkers Prev 2001;10:1155-63.

10 Miligi L, Costantini AS, Bolejack V, et al. Non-Hodgkin's lymphoma, leukemia, and exposures in agriculture: results from the Italian multicenter case-control study. Am J Ind Med 2003:44:627-36.

11 Pesatori AC, Sontag JM, Lubin JH, et al. Cohort mortality and nested case-control study of lung cancer among structural pest control workers in Florida (United States). Cancer Causes Control 1994;5:310-18.

12 Mills PK, Yang R. Prostate cancer risk in California farm workers. J Occup Environ Med 2003;45:249-58.

13 Alavanja MC, Dosemeci M, Samanic C, et al. Pesticides and lung cancer risk in the agricultural health study cohort. Am J Epidemiol 2004;160:876-85.

14 Beane Freeman LE, Bonner MR, Blair $A$, et al. Cancer incidence among male pesticide applicators in the Agricultural Health Study cohort exposed to diazinon. Am J Epidemiol 2005;162:1070-9.

15 Bonner MR, Williams BA, Rusiecki JA, et al. Occupational exposure to terbufos and the incidence of cancer in the Agricultural Health Study. Cancer Causes Control 2010;21:871-7.

16 Bonner MR, Coble J, Blair A, et al. Malathion exposure and the incidence of cancer in the agricultural health study. Am J Epidemiol 2007;166:1023-34.

17 Mahajan R, Blair A, Lynch CF, et al. Fonofos exposure and cancer incidence in the agricultural health study. Environ Health Perspect 2006;114:1838-42.

18 Alavanja MC, Hofmann JN, Lynch CF, et al. Non-hodgkin lymphoma risk and insecticide, fungicide and fumigant use in the agricultural health study. PLOS ONE 2014;9:e109332.

19 Koutros S, Beane Freeman LE, Lubin JH, et al. Risk of total and aggressive prostate cancer and pesticide use in the Agricultural Health Study. Am J Epidemiol 2013;177:59-74.

20 Van Tongeren M, Nieuwenhuiisen MJ, Gardiner K, et al. A job-exposure matrix for potential endocrine-disrupting chemicals developed for a study into the association between maternal occupational exposure and hypospadias. Ann Occup Hyg 2002;46:465-77

21 Crisp TM, Clegg ED, Cooper RL, et al. Environmental endocrine disruption: an effects assessment and analysis. Environ Health Perspect 1998;106(Suppl 1):11-56.

22 Pocar $\mathrm{P}$, Brevini TA, Fischer $\mathrm{B}$, et al. The impact of endocrine disruptors on oocyte competence. Reproduction 2003;125:313-25.

23 Siegel R, Ma J, Zou Z, et al. Cancer statistics, 2014. CA Cancer J Clin 2014;64:9-29.

24 Alavanja MC, Sandler DP, McMaster SB, et al. The Agricultural Health Study. Environ Health Perspect 1996;104:362-9.

25 Weichenthal S, Moase C, Chan P. A review of pesticide exposure and cancer incidence in the Agricultural Health Study cohort. Environ Health Perspect 2010;118:1117-25.

26 Goldner WS, Sandler DP, Yu F, et al. Hypothyroidism and pesticide use among male private pesticide applicators in the agricultural health study. J Occup Environ Med 2013;55:1171-8 
27 Goldner WS, Sandler DP, Yu F, et al. Pesticide use and thyroid disease among women in the Agricultural Health Study. Am J Epidemiol 2010;171:455-64.

28 Balasubramaniam S, Ron E, Gridley G, et al. Association between benign thyroid and endocrine disorders and subsequent risk of thyroid cancer among 4.5 million U.S. male veterans. J Clin Endocrinol Metab 2012;97:2661-9.

29 Franceschi S, Preston-Martin S, Dal Maso L, et al. A pooled analysis of case-control studies of thyroid cancer. IV. Benign thyroid diseases. Cancer Causes Control 1999;10:583-95.

30 Rinaldi S, Plummer M, Biessy C, et al. Thyroid-stimulating hormone, thyroglobulin, and thyroid hormones and risk of differentiated thyroid carcinoma: the EPIC study. J Natl Cancer Inst 2014;106:dju097.

31 Akhtar N, Kayani SA, Ahmad MM, et al. Insecticide-induced changes in secretory activity of the thyroid gland in rats. J App/ Toxicol 1996;16:397-400.

32 Ward MH, Kilfoy BA, Weyer PJ, et al. Nitrate intake and the risk of thyroid cancer and thyroid disease. Epidemiology 2010;21:389-95.

33 Koutros S, Alavanja MC, Lubin JH, et al. An update of cancer incidence in the Agricultural Health Study. J Occup Environ Med 2010;52:1098-105.

34 Zhang $X$, Wallace AD, Du P, et al. Genome-wide study of DNA methylation alterations in response to diazinon exposure in vitro. Environ Toxicol Pharmacol 2012;34:959-68

35 Mankame T, Hokanson R, Fudge R, et al. Altered gene expression in human cells treated with the insecticide diazinon: correlation with decreased DNA excision repair capacity. Hum Exp Toxicol 2006;25:57-65.

36 Andreotti G, Hoppin J, Savage S, et al. 0127 Pesticide use and relative telomere length in the Agricultural Health Study. Occup Environ Med 2014;71(Suppl 1): A14-15.

37 Kojima M, Fukunaga K, Sasaki M, et al. Evaluation of estrogenic activities of pesticides using an in vitro reporter gene assay. Int J Environ Health Res 2005; 15:271-80

38 Tisch $\mathrm{M}$, Schmezer $\mathrm{P}$, Faulde $\mathrm{M}$, et al. Genotoxicity studies on permethrin, DEET and diazinon in primary human nasal mucosal cells. Eur Arch Otorhinolaryngol 2002:259:150-3.

39 Engel LS, Hill DA, Hoppin JA, et al. Pesticide use and breast cancer risk among farmers' wives in the agricultural health study. Am J Epidemiol 2005;161:121-35.

40 Mills PK, Yang R. Breast cancer risk in Hispanic agricultural workers in California. Int J Occup Environ Health 2005;11:123-31.

41 Calaf GM, Echiburu-Chau C, Roy D. Organophosphorous pesticides and estrogen induce transformation of breast cells affecting p53 and c-Ha-ras genes. Int J Oncol 2009;35:1061-8.

42 Cabello G, Valenzuela M, Vilaxa A, et al. A rat mammary tumor model induced by the organophosphorous pesticides parathion and malathion, possibly through acetylcholinesterase inhibition. Environ Health Perspect 2001;109:471-9.

43 Kjeldsen LS, Ghisari M, Bonefeld-Jorgensen EC. Currently used pesticides and their mixtures affect the function of sex hormone receptors and aromatase enzyme activity. Toxicol App/ Pharmacol 2013;272:453-64.

44 Calaf GM, Echiburu-Chau C. Synergistic effect of malathion and estrogen on mammary gland carcinogenesis. Oncol Rep 2012;28:640-6.

45 Calaf GM, Roy D. Cancer genes induced by malathion and parathion in the presence of estrogen in breast cells. Int J Mol Med 2008;21:261-8.

46 Cantor KP, Blair A, Everett G, et al. Pesticides and other agricultural risk factors for non-Hodgkin's lymphoma among men in lowa and Minnesota. Cancer Res 1992;52:2447-55.
47 Pahwa M, Harris SA, Hohenadel K, et al. Pesticide use, immunologic conditions, and risk of non-Hodgkin lymphoma in Canadian men in six provinces. Int $\mathrm{J}$ Cancer 2012;131:2650-9.

48 Frost $\mathrm{G}$, Brown T, Harding AH. Mortality and cancer incidence among British agricultural pesticide users. Occup Med (Lond) 2011;61:303-10.

49 Bjorling-Poulsen M, Andersen HR, Grandjean P. Potential developmental neurotoxicity of pesticides used in Europe. Environ Health 2008;7:50.

50 Rani CS, Field JB. Comparison of effects of thyrotropin, phorbol esters, norepinephrine, and carbachol on iodide organification in dog thyroid slices, follicles, and cultured cells. Endocrinology 1988;122:1915-22.

51 Melander A, Ericson LE, Sundler F, et al. Intrathyroidal amines in the regulation of thyroid activity. Rev Physiol Biochem Pharmacol 1975;73:39-71.

52 Yuan YD, Seak CJ, Lin CC, et al. Thyroid storm precipitated by organophosphate intoxication. Am J Emerg Med 2007;25:861.e1-3.

53 Lacasana M, Lopez-Flores I, Rodriguez-Barranco M, et al. Association between organophosphate pesticides exposure and thyroid hormones in floriculture workers. Toxicol Appl Pharmacol 2010;243:19-26.

54 Abdollahi M, Mostafalou S, Pournourmohammadi S, et al. Oxidative stress and cholinesterase inhibition in saliva and plasma of rats following subchronic exposure to malathion. Comp Biochem Physiol C Toxicol Pharmacol 2004;137:29-34.

55 Akhgari M, Abdollahi M, Kebryaeezadeh A, et al. Biochemical evidence for free radical-induced lipid peroxidation as a mechanism for subchronic toxicity of malathion in blood and liver of rats. Hum Exp Toxicol 2003;22:205-11.

56 John $\mathrm{S}$, Kale $\mathrm{M}$, Rathore $\mathrm{N}$, et al. Protective effect of vitamin $\mathrm{E}$ in dimethoate and malathion induced oxidative stress in rat erythrocytes. I Nutr Biochem 2001;12:500-4.

57 Galloway T, Handy R. Immunotoxicity of organophosphorous pesticides. Ecotoxicology 2003;12:345-63.

58 Kang HG, Jeong SH, Cho JH, et al. Chlropyrifos-methyl shows anti-androgenic activity without estrogenic activity in rats. Toxicology 2004;199:219-30.

59 Tamura H, Maness SC, Reischmann K, et al. Androgen receptor antagonism by the organophosphate insecticide fenitrothion. Toxicol Sci 2001;60:56-62.

60 Usmani KA, Cho TM, Rose RL, et al. Inhibition of the human liver microsomal and human cytochrome P450 1A2 and 3A4 metabolism of estradiol by deployment-related and other chemicals. Drug Metab Dispos 2006;34:1606-14.

61 Usmani KA, Rose RL, Hodgson E. Inhibition and activation of the human live microsomal and human cytochrome P450 3A4 metabolism of testosterone by deployment-related chemicals. Drug Metab Dispos 2003;31:384-91.

62 Platz EA, Giovannucci E. The epidemiology of sex steroid hormones and their signaling and metabolic pathways in the etiology of prostate cancer. I Steroid Biochem Mol Biol 2004;92:237-53.

63 Hatch EE, Nelson JW, Stahlhut RW, et al. Association of endocrine disruptors and obesity: perspectives from epidemiological studies. Int J Androl 2010;33:324-32.

64 Andreotti G, Hou L, Beane Freeman LE, et al. Body mass index, agricultural pesticide use, and cancer incidence in the Agricultural Health Study cohort. Cancer Causes Control 2010:21:1759-75.

65 Blair A, Tarone R, Sandler D, et al. Reliability of reporting on life-style and agricultural factors by a sample of participants in the Agricultural Health Study from lowa. Epidemiology 2002;13:94-9.

66 Colt JS, Cyr MJ, Zahm SH, et al. Inferring past pesticide exposures: a matrix of individual active ingredients in home and garden pesticides used in past decades. Environ Health Perspect 2007;115:248-54. 